\title{
Má oclusão e fonoaudiologia e fatores associados: revisão integrativa
}

\author{
Malocclusion and speech therapy and associated factors: integrative review \\ Malocclusión y fonoaudiología y factores asociados: revisión integrativa
}

Recebido: 06/01/2021 | Revisado: 07/01/2021 | Aceito: 11/01/2021 | Publicado: 13/01/2021

Flávia da Silva Martins

ORCID: https://orcid.org/0000-0002-6652-3061 Faculdade de Ensino Superior do Piaú, Brasil E-mail: flavianumberone01@ @otmail.com

Marcilene Ferreira da Silva

ORCID: https://orcid.org/0000-0002-1118-8526 Faculdade de Ensino Superior do Piauí, Brasil E-mail: marcyleneferreira20@gmail.com

Danilo Sampaio Souza

ORCID: https://orcid.org/0000-0002-0216-3669 Faculdade de Ensino Superior do Piauí, Brasil E-mail: danilosampaio16@hotmail.com

Ruth Raquel Soares de Farias

ORCID: https://orcid.org/0000-0002-0988-0900 Faculdade de Ensino Superior do Piauí, Brasil E-mail: ruthraquelsf@gmail.com

Priscila Figueiredo Cruz Ramos

ORCID: https://orcid.org/0000-0002-8188-3559

Faculdade de Ensino Superior do Piauí, Brasil E-mail: priscilaafc@hotmail.com

\begin{abstract}
Resumo
A má oclusão pode ser definida como o alinhamento anormal dos dentes ou uma má relação entre os arcos dentários, da maneira pela qual os dentes superiores e inferiores se encaixam, causando assim alterações estruturais e funcionais. Avaliar o perfil de má oclusão e fatores associados de indivíduos em tratamento fonoaudiológico por meio de revisão de literatura. Para realização da pesquisa, escolheu-se o método de revisão integrativa, com abordagem qualitativa, foi realizado levantamento bibliográfico por meio de consulta nas bases de dados: Lilacs, Scielo e Pubmed. Os descritores utilizados na pesquisa foram: Epidemiologia, Ortodontia, Fonoaudiologia. Como critério de inclusão foram estabelecidos artigos científicos completos somente em língua portuguesa e inglesa, entre os anos de 2015 a 2020. Após a seleção dos resumos de estudos encontrados, cinco foram inclusos no estudo. Após realizada pesquisa nas bases de dados, formam encontrados cento e cinquenta artigos, sendo Pubmed 70; Lilacs 41; Scello 44. Após estudos dos títulos e resumos incoerentes ao tema, foram excluídos 114 e 26 eliminados por duplicação, foram selecionados por elegibilidade 20, após a leitura na integra, a amostra foi constituída por cinco artigos científicos, selecionados pelos critérios de inclusão previamente estabelecidos. Após a análise dos artigos selecionados para esta revisão, com o objetivo de facilitar a leitura e compreensão, os resultados foram agrupados em categorias: nível de evidência, classificação de oclusão e fatores associados. Conclui-se que a atuação interdisciplinar entre a odontologia e a fonoaudiologia é relevante para o restabelecimento estético e funcional.
\end{abstract}

Palavras-chave: Má oclusão; Interdisciplinaridade; Sistema estomatognático.

\begin{abstract}
Malocclusion can be defined as the abnormal alignment of teeth or a poor relationship between dental arches so that the upper and lower teeth fit together, thus causing structural and functional changes. To evaluate the profile of malocclusion and associated factors of individuals undergoing speech therapy through a literature review. For conducting the research, the method of integrative review was chosen, with a qualitative approach, a bibliographic survey was carried out by consulting the databases: Lilacs, Scielo and Pubmed. The descriptors used in the research were Epidemiology, Orthodontics, and Speech Therapy. As an inclusion criterion, complete scientific articles were established only in Portuguese and English, in the years 2015 to 2020. After selecting the study abstracts found, five were included in the study. After searching the databases, one hundred and fifty articles were found, Pubmed 70, Lilacs 41, Scello 44, after studies of titles and abstracts inconsistent with the theme, 114 and 26 were excluded due to duplication, were selected for eligibility 20, after full reading of the sample consisted of five scientific articles, selected by the inclusion criteria previously established. After analyzing the articles selected for this review, in order to facilitate reading and understanding, the results were grouped into categories: level of evidence, classification of occlusion and associated factors. It is concluded that the interdisciplinary work between dentistry and speech therapy is relevant for the aesthetic and functional restoration.
\end{abstract}


Keywords: Malocclusion; Interdisciplinarity; Stomatognathic system.

\section{Resumen}

La maloclusión se puede definir como la alineación anormal de los dientes o una mala relación entre las arcadas dentarias para que los dientes superiores e inferiores encajen entre sí, provocando cambios estructurales y funcionales. Evaluar el perfil de maloclusión y factores asociados de individuos sometidos a logopedia a través de una revisión de la literatura. Para la realización de la investigación se eligió el método de revisión integradora, con un enfoque cualitativo, se realizó un levantamiento bibliográfico consultando las bases de datos: Lilacs, Scielo y Pubmed. Los descriptores utilizados en la investigación fueron Epidemiología, Ortodoncia, Logopedia. Como criterio de inclusión, se establecieron artículos científicos completos únicamente en portugués e inglés, en los años 2015 a 2020 . Luego de seleccionar los resúmenes de estudio encontrados, cinco fueron incluidos en el estudio. Después de buscar en las bases de datos, se encontraron ciento cincuenta artículos, Pubmed 70, Lilacs 41, Scello 44, luego de que se excluyeran estudios de títulos y resúmenes inconsistentes con el tema, 114 y 26 por duplicación, se seleccionaron para elegibilidad 20, luego La lectura completa de la muestra estuvo compuesta por cinco artículos científicos, seleccionados por los criterios de inclusión previamente establecidos. Luego de analizar los artículos seleccionados para esta revisión, con el fin de facilitar la lectura y comprensión, los resultados se agruparon en categorías: nivel de evidencia, clasificación de la oclusión y factores asociados. Se concluye que el trabajo interdisciplinario entre odontología y logopedia es relevante para la restauración estética y funcional.

Palabras clave: Maloclusión; Interdisciplinariedad; Sistema estomatognático.

\section{Introdução}

Má oclusão é o terceiro maior problema relacionado à saúde bucal, segundo dados da Organização Mundial de Saúde (OMS, 2017). A má oclusão pode ser definida como o alinhamento anormal dos dentes ou uma má relação entre os arcos dentários de maneira pela qual os dentes superiores e inferiores se encaixam, causando assim alterações estruturais e funcionais (Gupta et al., 2016). Em relação ao sistema estomatognático, a má oclusão caracteriza-se pelo desequilíbrio entre a intercuspidação dentária com um desvio da normalidade do sistema. (Narayanan et al.,2016).

A Fonoaudiologia é uma ciência responsável pelo estudo da comunicação humana, que abrange os aspectos das funções orais, estomatognáticas, auditivas, cognitivas. Também está presente no estudo da linguagem oral e escrita, da fala, da fluência, da voz (CFFa, 6REGIÃO, 2015).

A prevalência de má oclusão pode variar de acordo com a faixa etária e com a metodologia do estudo, podendo ter uma prevalência de 70,1\% na faixa etária de 7 a 14 anos (Marcomini et al., 2010). Observa-se também a relação da má oclusão com fatores associados como alterações na fala, deglutição, mastigação e na respiração (Marcomini et al., 2010; Pereira et al., 2016; Caetano, 2019; Sara et al., 2019). Com isso a importância de um tratamento interdisciplinar entre os profissionais de fonoaudiologia e ortodontia com suprir as necessidades e com isso a reabilitação do paciente e o equilíbrio mio funcional do sistema estomatognático (Canto et al.,2014).

Por essa razão, sabendo-se que um bom funcionamento com integridade e equilíbrio do sistema estomatognático é o que se busca para os pacientes, a fonoaudiologia em conjunto com a ortodontia realiza importantes avaliações e tratamentos morfofuncionais na intenção de corrigir os desvios das funções do sistema estomatognático, e promover assim uma melhor qualidade de vida para esses pacientes (Amaral et al., 2015). A fonoaudiologia é, realmente, uma grande aliada da ortodontia, sendo que ambas as partes tem como objetivo principal o resultado do sistema estomatognático equilibrado, estável e uma face mais harmoniosa do ponto de vista estético (Carvalho, 2015).

Considerando a relevância do trabalho interdisciplinar entre a Fonoaudiologia e Ortodontia, ambas se completam e devem caminhar juntas para o reequilíbrio mio funcional. Este trabalho foi realizado com a necessidade de identificar os fatores associados a má oclusão dos indivíduos, analisar a prevalência de má oclusão dos indivíduos e caracterizar a avaliação fonoaudiológica em relação ao sistema estomatognático. Pois a literatura ainda é carente de estudos que tracem o perfil de má oclusão entre as áreas, o que deve ser consolidado e ampliado nos âmbitos das instituições acadêmicas, estabelecendo-se uma aproximação entre as duas áreas. (Silva et al.,2014). Em função desta constatação, o objetivo desse estudo foi analisar o perfil 
de má oclusão e fatores associados em indivíduos em tratamento fonoaudiológico por meio de uma revisão de literatura integrativa.

\section{Metodologia}

\subsection{Tipo de pesquisa}

Esta pesquisa foi do tipo revisão integrativa, uma pesquisa que utiliza como fonte de dados a literatura sobre um determinado tema. Esta permite a análise de subsídios na literatura de forma ampla e sistemática, além de divulgar dados científicos produzidos por outros autores (Ramalho et al.,2016). Com a abordagem qualitativa e quantitativa que tenta compreender certos "fenômenos" comportamentais da coleta de dados narrativos e estudando as preferências individuais de cada um (Pereira et al., 2018).

Portanto, foi desenvolvida com as seguintes fases: construção da pergunta norteadora; busca ou amostragem da literatura; coleta de dados; análise crítica dos estudos incluídos; discussão dos resultados e apresentação da revisão integrativa. A pergunta que norteou a pesquisa foi: Qual a relação da classificação oclusal e ou fatores associados dos pacientes em tratamento fonoaudiológico? Para responder à questão norteadora, a pesquisa foi realizada por meio de um levantamento bibliográfico, por meio de consulta direta na internet através de dados online disponíveis nas seguintes bases de dados: LILACS, SCIELO e PUBMED.

Foram utilizados os descritores indexados no Dicionário de Ciências e Saúde (DECS) na pesquisa: Epidemiologia (epidemiology), Ortodontia (orthodontics), Fonoaudiologia (speech therapy). Estas foram combinadas entre si por meio dos operadores boleanos "AND" e "Or". A busca dos artigos foi por meio de combinações, sendo elas; Epidemiologia (epidemiology) AND Ortodontia (orthodontics), Epidemiologia (epidemiology)AND Fonoaudiologia (speech therapy), Epidemiologia (epidemiology) OR Ortodontia (orthodontics) AND Fonoaudiologia (speech therapy), Fonoaudiologia (speech therapy) OR Ortodontia (orthodontics), Fonoaudiologia (speech therapy) AND Ortodontia (orthodontics).

\subsection{Critérios de seleção}

Os artigos foram analisados e selecionados de acordo com critérios de inclusão e exclusão e organizados no fluxograma, o processo de identificação de artigos de acordo com o PRISMA (Figura 1). Dentre os critérios de inclusão foram estabelecidos artigos científicos completos somente na língua portuguesa e inglesa, nos anos de 2015 a 2020 . E os critérios de exclusão foram os artigos cuja a temática não se adequavam ao tema proposto e artigos duplicados. Após o levantamento, os artigos foram separados e analisados, conforme título e resumo que remetessem à temática pesquisada.

\subsection{Análise dos artigos}

Após a escolha e análise dos artigos selecionados, contendo os nomes dos autores; ano de publicação; objetivos; metodologia, os resultados encontrados foram organizados em uma tabela (Tabela 1). Sendo que tanto a análise quanto a síntese dos dados extraídos dos artigos foram de forma descritiva, possibilitando observar, contar, descrever e classificar os dados com intuito de reunir o conhecimento produzido sobre o tema explorado na revisão.

Os artigos foram analisados de acordo com o nível de evidência, classificação de oclusão e fatores associados. Os níveis de evidências foram divididos em seis níveis, sendo o nível 1, os estudos meta-análise de múltiplos estudos clínicos controlados e randomizados; o nível 2 e 3, de estudos com delineamento experimentais, quase-experimentais, respectivamente; nível 4, estudos descritivos; nível 5, são estudos de relato de caso e de experiência; e nível 6, estudos de opinião de especialistas (Steler et al.,1998).

A classificação de oclusão foi avaliada por meio de medidas de alteração horizontal, vertical e transversal como está descrito no Quadro 1 (Moyers, 1991). A atuação fonoaudiológica foi avaliada quanto às alterações da função (respiração, 
suç̧ão, mastigação, deglutição, fonoarticulação), das estruturas (lábios, língua, bochechas, palato duro, palato mole, dentes), do sistema estomatognático (Tabela 2). Os fatores associados foram avaliados quanto à presença de hábitos deletérios e ao uso de mamadeira, chupeta, que interfere no sistema estomatognático (Tabela 2).

Quadro 1. Classificação de oclusão.

\begin{tabular}{|l|l|}
\hline \multirow{3}{*}{ Alteração horizontal } & $\begin{array}{l}\text { Sobressaliência: Distância entre as bordas dos incisais dos incisivos superiores e inferiores } \\
\text { paralelo ao plano oclusal. }\end{array}$ \\
\cline { 2 - 3 } Alteração vertical & $\begin{array}{l}\text { Mordida cruzada anterior: Definida pela presença de um trespasse horizontal negativo na região } \\
\text { de incisivos e caninos, envolvendo um ou mais dentes }\end{array}$ \\
\cline { 2 - 3 } & $\begin{array}{l}\text { Sobremordida: Distância entre as bordas dos incisais superiores e inferiores perpendicular ao } \\
\text { plano oclusal. }\end{array}$ \\
\cline { 2 - 3 } & $\begin{array}{l}\text { Mordida aberta: Distância perpendicular ao plano oclusal, entre as bordas incisais dos incisivos } \\
\text { superiores e inferiores, é menor que zero. }\end{array}$ \\
\hline Alteração transversal & $\begin{array}{l}\text { Mordida cruzada posterior: Quando indicar um relação vestibulolingual ou laterolateral anormal } \\
\text { de um dente ou grupo de dentes posteriores superior e inferior. }\end{array}$ \\
\hline
\end{tabular}

Fonte: Moyers (1991).

O Quadro 1 mostra a classificação de oclusão avaliada por meio de medidas de alteração horizontal, vertical e transversal, tais alterações que influenciam no sistema estomatognático.

\section{Resultados}

Esse estudo teve como objetivo avaliar o perfil de má oclusão e fatores associados de indivíduos em tratamento fonoaudiológico por meio de revisão de literatura. Após realizada pesquisa nas bases de dados Pubmed, 70 artigos foram encontrados; na Scielo, 44; Lilacs, 41, totalizando 155 artigos encontrados e revisados de acordo com o título e resumo. Foram incluídos apenas aqueles que não atenderam aos critérios de elegibilidade do estudo, removeram-se 26 artigos duplicados e excluíram-se 114, por títulos e resumos. Artigos lidos na integra, após resumos, 20 foram incluídos na amostra final desta revisão, constituída por 5 artigos científicos, selecionados pelos critérios de inclusão previamente estabelecidos (Figura 1). Destes, 2 foram encontrados na base de dados Pubmed e 3 na Lilacs. Durante a seleção dos artigos utilizados na presente pesquisa, houve a necessidade da elaboração de uma tabela na qual são inseridos as referências; o tipo de metodologia; os objetivos e os principais resultados presentes das fontes consultadas (Tabela 1). Após a análise dos artigos selecionados para esta revisão, os resultados foram agrupados em categorias; referencias; nível de evidencia; classificação de oclusão; fatores que influenciavam o sistema estomatognático e a avaliação fonoaudiológica (Tabela 2). 
Figura 1. Fluxograma do processo de identificação de artigos de acordo com o PRISMA.

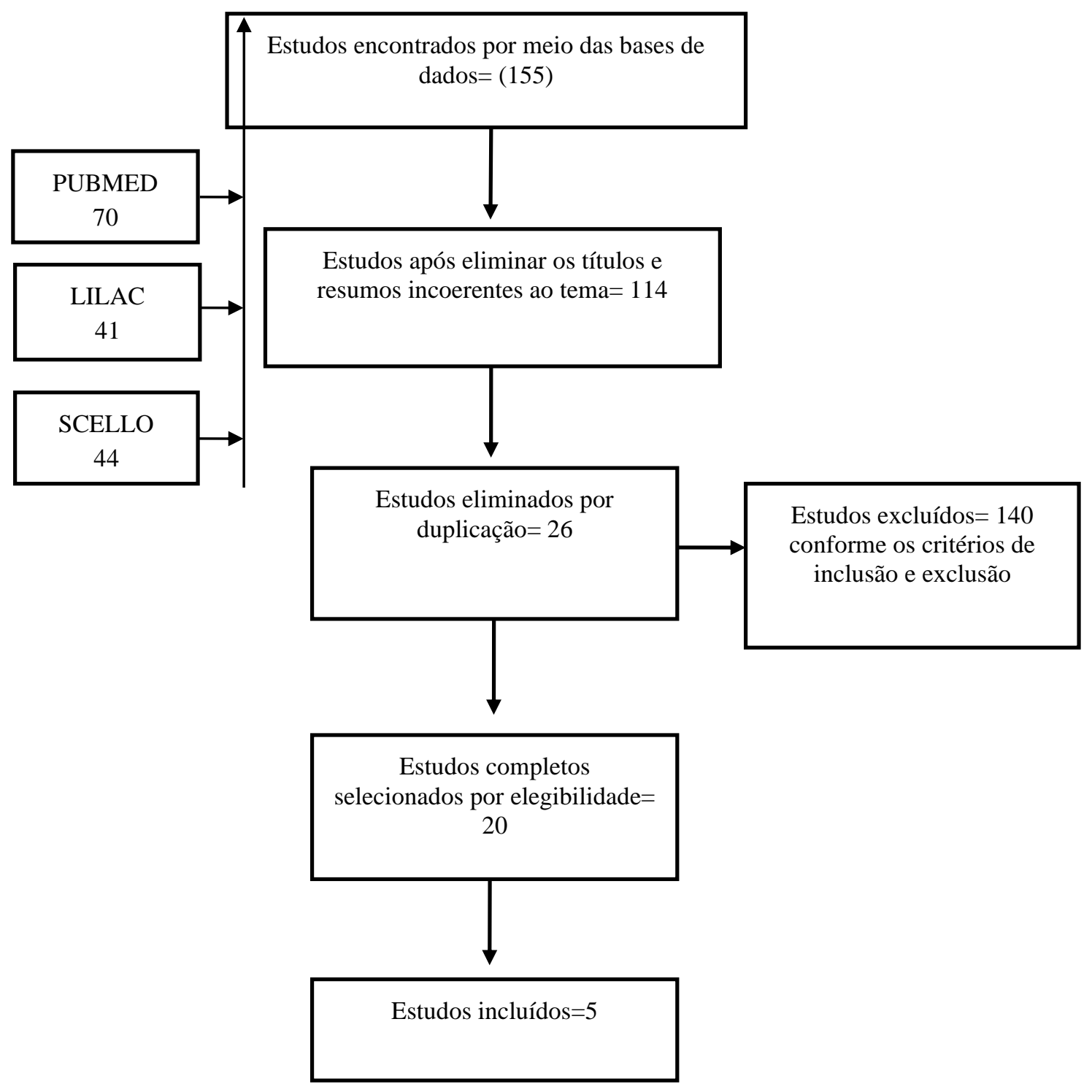

Fonte: Autores.

Após realizada pesquisa nas bases de dados. Os artigos lidos na integra foram incluídos na amostra final desta revisão, selecionados pelos critérios de inclusão previamente estabelecidos (Figura 1). 
Tabela 1. Relação de Artigos de acordo com Autores.

\section{Referência \\ Metodologia \\ Objetivo \\ Principais resultados}

\begin{tabular}{|c|c|c|c|}
\hline $\begin{array}{c}\text { Carminatti et al } \\
\text { (2016) }\end{array}$ & Estudo transversal & $\begin{array}{l}\text { Foi associar a cárie } \\
\text { dentária, má oclusão e } \\
\text { hábitos orais com a } \\
\text { qualidade de vida de } \\
\text { crianças pré-escolares e } \\
\text { seus familiares }\end{array}$ & $\begin{array}{l}\text { A cárie dentária apresentou impacto sobre a } \\
\text { qualidade de vida das crianças e de seus } \\
\text { familiares, especialmente em relação aos domínios } \\
\text { dos sintomas e limitações. Hábitos de respiração } \\
\text { oronasal e chupeta também evidenciaram efeitos } \\
\text { negativos na qualidade de vida das crianças e de } \\
\text { seus familiares. }\end{array}$ \\
\hline Pereira et al (2017) & $\begin{array}{l}\text { Estudo transversal } \\
\text { caráter exploratório }\end{array}$ & $\begin{array}{l}\text { Verificar a ocorrência e } \\
\text { associar a presença e a } \\
\text { manutenção de hábitos } \\
\text { orais deletérios com as } \\
\text { estruturas e funções do } \\
\text { sistema estomatognático. }\end{array}$ & $\begin{array}{l}\text { Os hábitos mais prevalentes e mantidos atualmente } \\
\text { foram a mamadeira }(28,62 \%) \text { e a chupeta } \\
(23,18 \%) \text { convencional. Houve associação } \\
\text { significativa entre o fato de a criança permanecer } \\
\text { com a boca aberta e respirar de modo oral e } \\
\text { oronasal. A presença de hábitos como a } \\
\text { mamadeira e a chupeta ortodôntica estava } \\
\text { relacionada ao modo respiratório relatado. O } \\
\text { tempo de manutenção dos hábitos estava associado } \\
\text { à percepção da presença de alterações na fala e } \\
\text { oclusais. }\end{array}$ \\
\hline Costa et al (2015) & $\begin{array}{l}\text { Estudo } \\
\text { retrospectivo }\end{array}$ & $\begin{array}{l}\text { Descrever os achados } \\
\text { miofuncionais orofaciais, } \\
\text { bem como os principais } \\
\text { problemas otorrinolaringo- } \\
\text { lógicos, alergológicos e } \\
\text { ortodônticos encontrados } \\
\text { em crianças com respiração } \\
\text { oral. }\end{array}$ & $\begin{array}{l}\text { Observou-se prevalência significante de } \\
\text { permanência de boca aberta }(98,0 \%) \text {, ronco } \\
(89,9 \%) \text { e sialorreia noturna }(68,6 \%) \text {. A avaliação } \\
\text { ortodôntica indicou presença de má oclusão } \\
(86,8 \%) \text {, perfil facial convexo }(62,9 \%) \text { e trespasse } \\
\text { vertical aumentado ( } 55,5 \%) \text {. Os dados da } \\
\text { avaliação fonoaudiológica indicaram inadequação } \\
\text { da posição habitual de lábios }(70,5 \%) \text {, tensão de } \\
\text { lábios }(65,4 \%) \text { e de língua }(64,4 \%) \text { alteradas, } \\
\text { palato duro alto (57,1\%), ângulo nasolabial } \\
\text { alterado }(57,0 \%) \text { e assimetria facial }(55,0 \%) \text {. }\end{array}$ \\
\hline $\begin{array}{l}\text { Inagaki et al } \\
\text { (2015) }\end{array}$ & Relato de caso & $\begin{array}{lr}\text { Apresentar o } & \text { tratamento } \\
\text { interdisciplinar } & \text { entre } \\
\text { Odontologia } & \text { e } \\
\text { Fonoaudiologia em } & \text { uma } \\
\text { criança de idade pré- } \\
\text { escolar, com cárie precoce } \\
\text { da infância. }\end{array}$ & $\begin{array}{l}\text { Confirmou-se dificuldade de mobilidade dos } \\
\text { lábios e língua com diminuição do tônus da } \\
\text { bochecha e alterações na fala. A terapia } \\
\text { fonoaudiológica foi estabelecida durante três } \\
\text { meses com periodicidade semanal, havendo } \\
\text { melhora em todos os aspectos alterados, } \\
\text { confirmados pela adequação dos escores do } \\
\text { Protocolo MBGR. No tratamento odontológico } \\
\text { foram observados resultados clinicamente } \\
\text { satisfatórios para a criança e responsáveis. }\end{array}$ \\
\hline Silva et al (2015) & $\begin{array}{l}\text { Descritiva } \\
\text { retrospectiva de } \\
\text { corte transversal, }\end{array}$ & $\begin{array}{l}\text { Caracterizar as funções } \\
\text { orofaciais de mastigação, } \\
\text { deglutição e respiração das } \\
\text { crianças, e relacioná-las } \\
\text { com o tipo de má oclusão e } \\
\text { com a tipologia facial. }\end{array}$ & $\begin{array}{l}\text { Verificou-se maior frequência de mastigação do } \\
\text { tipo unilateral }(60 \%) \text { com posição de lábios } \\
\text { abertos }(83,3 \%) \text {; deglutiçãa com contração de } \\
\text { mentual (56,7\%); respiração do tipo nasal } \\
(63,3 \%) \text {; alterações verticais de oclusão }(40 \%) \text {; e } \\
\text { face longa }(36,7 \%) \text {. }\end{array}$ \\
\hline
\end{tabular}

Fonte: Autores (2020). 
A Tabela 1 demostra de modo as referências, o tipo de metodologia, os objetivos e os principais resultados, encontrados nas presentes fontes consultadas.

Tabela 2. Relação de Artigos de acordo com as categorias.

\begin{tabular}{|c|c|c|c|c|}
\hline Referência & $\begin{array}{l}\text { Nível de } \\
\text { evidência }\end{array}$ & $\begin{array}{c}\text { Classificação de } \\
\text { oclusão }\end{array}$ & $\begin{array}{c}\text { Fatores que } \\
\text { influenciavam o } \\
\text { sistema } \\
\text { estomatognáticos }\end{array}$ & Avaliação fonoaudiológica \\
\hline
\end{tabular}

\begin{tabular}{|c|c|c|c|c|}
\hline $\begin{array}{l}\text { Costa et al } \\
(2015)\end{array}$ & Nível 4 & $\begin{array}{l}\text { Trespasse vertical } \\
\text { aumentado( } 55,5 \%) \text { e } \\
\text { presenca de má } \\
\text { oclusão( } 85,8 \%) \text { classe } \\
\text { I em } 168(33,5 \%) \\
\text { casos, seguido de } \\
\text { classe II divisão } 1 \text { em } \\
163(32,5 \%) \text {, classe III } \\
\text { em } 46(9,2 \%) \text { e classe } \\
\text { II subdivisão } 2 \text { em seis } \\
\text { casos }(1,2 \%) \text {. }\end{array}$ & $\begin{array}{l}\text { Problemas } \\
\text { respiratórios } \\
\text { (Presença de rinite) } \\
\text { Alterações nas } \\
\text { funções e estruturas } \\
\text { estomatognáticas. } \\
\text { Alterações } \\
\text { ortodônticas }\end{array}$ & $\begin{array}{l}\text { Avaliação das funções estomatog- } \\
\text { náticas, } 23,9 \% \text { foram encontradas } \\
\text { distorções na fala, substituições de } \\
\text { fonemas em } 13,3 \% \text { e omissões em } 11 \% \\
\text { dos casos. Travamento mandibular e } \\
\text { salivação excessiva ocorreram em } \\
\text { menos de } 1 \% \text { dos casos cada. }\end{array}$ \\
\hline $\begin{array}{l}\text { Pereira et al } \\
(2017)\end{array}$ & Nível 3 & $\begin{array}{l}\text { Dentes abertos na } \\
\text { frente, mordida } \\
\text { cruzada. }\end{array}$ & $\begin{array}{l}\text { Ocorrência de } \\
\text { hábitos deletérios, } \\
\text { associação com } \\
\text { alterações na fala e } \\
\text { alterações oclusais }\end{array}$ & $\begin{array}{l}\text { Foram consideradas alterações de fala } \\
\text { as descritas pelos responsáveis } \\
\text { relacionadas à produção dos fones (/t/ } \\
/ \mathrm{d} /, / \mathrm{n} /, / \mathrm{l} /, / \mathrm{r} /, / \mathrm{s} / \text { e } / \mathrm{z} /) \text {. }\end{array}$ \\
\hline $\begin{array}{l}\text { Inagaki et al } \\
(2015)\end{array}$ & Nível 5 & $\begin{array}{l}\text { Dentição decídua, com } \\
\text { presença de lesão } \\
\text { cariosa na superfície } \\
\text { oclusal dos dentes } 64 \text {, } \\
84,85,74,75 \text { e terços } \\
\text { médio e incisal } \\
\text { vestibular dos dentes } \\
51,61 \text {. (Estes com } \\
\text { história de trauma } \\
\text { anterior), } 52 \text { e } 62 .\end{array}$ & $\begin{array}{l}\text { Cárie } \\
\text { Dificuldades de } \\
\text { produção de } \\
\text { algumas palavras. } \\
\text { Alterações nas } \\
\text { funções e estruturas } \\
\text { estomatognáticas }\end{array}$ & $\begin{array}{l}\text { Tônus de bochecha diminuído, língua } \\
\text { com altura aumentada, dificuldade de } \\
\text { mobilidade, sendo que a paciente não } \\
\text { conseguia lateralizar o lábio em } \\
\text { protrusão direita e esquerda, e também } \\
\text { vibrar a língua. Em relação às funções } \\
\text { orofaciais, na mastigação a paciente } \\
\text { apresentou fechamento labial } \\
\text { assistemático, velocidade aumentada e } \\
\text { presença de contrações musculares } \\
\text { atípicas. }\end{array}$ \\
\hline $\begin{array}{l}\text { Silva et al } \\
(2015)\end{array}$ & Nível 4 & $\begin{array}{l}\text { Alterações verticais de } \\
\text { oclusão, } \\
\text { especificamente a } \\
\text { sobremordida e a } \\
\text { mordida aberta } \\
\text { anterior, em } 20 \% \text { e } \\
16,7 \% \\
\text { respectivamente. }\end{array}$ & $\begin{array}{l}\text { Alterações nas } \\
\text { funções e estruturas } \\
\text { estomatognáticas. } \\
\text { Alterações } \\
\text { ortodônticas }\end{array}$ & $\begin{array}{l}\text { Assimetria de bochechas, em } 63,3 \% \text {. } \\
\text { Tônus de mentual, } 40 \% \text { diminuído e } \\
\text { aumentado. Tônus de lábios, que } \\
\text { apresentou diminuído em } 46,7 \% \text {. } \\
\text { Mastigação tipo unilateral }(60 \%) \text { com } \\
\text { posição de lábios abertos }(83,3 \%) \text {. } \\
\text { Deglutição } 70 \% \text { alteração, }(56,7 \%) \text {. } \\
\text { Respiração tipo nasal }(63,3 \%) .\end{array}$ \\
\hline
\end{tabular}

Fonte: Autores (2020).

A Tabela 2 os resultados foram agrupados em categorias: referências, nível de evidência, classificação de oclusão, fatores que influenciavam o sistema estomatognático e avaliação fonoaudiológica. 


\section{Discussão}

Esse estudo teve como objetivo avaliar o perfil de má oclusão e fatores associados de indivíduos em tratamento fonoaudiológico por meio de revisão de literatura. As referências selecionadas permitiram a discussão dos objetivos propostos pelo estudo. Sabe-se que diversas alterações podem ser percebidas em um indivíduo com má oclusão. Fatores estes que levam a alterações no sistema estomatognático que acarretam distúrbios no crescimento dento facial, sucção, mastigação, deglutição e na fala dos indivíduos.

Após a análise dos artigos, evidenciaram estudos com nível 3, que caracteriza estudo com evidências quase experimentais (Pereira et al., 2015), caracterizados quanto ao nível 4 os estudos têm como evidências descritivos com abordagem qualitativa (Costa; Silva et al., 2015) quanto ao nível 5, evidências provenientes de relatos de casos de experiências (Inagaki et al., 2017).

Os aspectos relacionados ao desenvolvimento à oclusão devem ser considerados quanto a forma e função e qualquer alteração poderá levar a um desequilíbrio, acarretando alterações diversas. Essas informações somam-se às dos autores (Silva; Costa, et al., 2015). As más oclusões se baseiam na relação anteroposterior dos maxilares, utilizada em dentadura mista e permanente com presença dos primeiros molares superiores e inferiores permanentes (Angle, 1907). A porcentagem avaliada nos estudos quanto a presença de má oclusão foi de 86,8\% (Costa \& Silva et al., 2015).

Podem ser encontrados vários problemas, que podem aparecer isolados ou concomitantes dentre eles: mordida cruzada, mordida aberta, sobremordida profunda, sobressaliência aumentada, apinhamentos dentais, presença de hábitos bucais deletérios e perdas precoces dentais (Moyers, 1991). Alterações verticais de oclusão, especificamente a sobremordida e a mordida aberta anterior estão relacionadas, aos distúrbios miofuncionais, a ação da fonoaudiologia ocorrerá após a correção ortodôntica, visto a alteração da forma limita as funções (Silva et al., 2015). Dentre eles o perfil facial convexo (62,9\%) e trespasse vertical aumentado 55,5\% (Costa et al.,2015). Outro estudo verificou maior frequência de alterações verticais de oclusão, especificamente a sobremordida $20 \%$ e a mordida aberta anterior 16,75, observou-se maior frequência para face longa, 36,7\% (Silva et al., 2015).

As más oclusões são de etiologia multifatoriais, podendo ser genéticas ou ambiental, onde estes fatores ambientais não têm influência com genética e são mais fáceis de identificar e geram grande efeito nas más oclusões (Costa et al., 2015). Entre os fatores, que influenciaram, estavam relacionados às causas viciosas como sucção digital, sugar língua, o uso de chupeta, mamadeira, são atribuídas hábitos deletérios, uso de chupetas e bicos de mamadeira inadequados esses fatores contribuem para deformações anatômicas das estruturas orais, com o consequente desencadeamento nas funções orais (Pereira et al., 2016). Desencadeando a prevalência nas alterações estruturais como interposição labial inferior com contração do músculo mentual durante a deglutição, sendo observadas alterações na fala envolvendo a produção de sons bilabiais e fricativos, travamento mandibular e salivação excessiva realizada pelo contato do lábio inferior contra a arcada dentária superior, para que ocorra o vedamento labial, essas funções e estruturas devem estar íntegras (Costa; Silva et al., 2015). Outro estudo avaliou que a falta de dentes, causada pela cárie, está associada a qualidade de vida social e psicológicos, interfere na capacidade de se alimentar com ocorrência de dor e desconforto são considerados aspectos negativos mais relevante para a qualidade de vida. (Carminatti et al., 2017).

Em relação aos dados da avaliação fonoaudiológica indicaram inadequação da posição habitual de lábios (70,5\%), tensão de lábios $(65,4 \%)$ e de língua $(64,4 \%)$ alteradas, palato duro alto (57,1\%), ângulo nasolabial alterado (57,0\%) e assimetria facial $(55,0 \%)$ causando diminuição do tamanho da via aérea respiratória, e obstrução, como a presença de renites, hipertrofia de adenoide e amígdalas, além de mucosa nasal alterada e os desvios de septo nasal (Costa et al.,2015). Outro estudo verificou maior frequência para a assimetria de bochechas, em 63,3\% da amostra. Quanto ao tônus de mentual, 40\%, da amostra apresentou alteração, considerando tônus da língua apresentou diminuído 46,7\%. Verificou-se que a função de 
mastigação apresentou maior frequência do tipo unilateral (60\%) com posição de lábios abertos (83,3\%). Quanto à deglutição, observou-se que $70 \%$ da amostra apresentou alteração, sendo a contração de mentual a mais frequente $(56,7 \%)$. Em relação à respiração se averiguou o tipo nasal 63,3\% (Silva et al., 2015).

O sistema estomatognático necessita de aspecto anatômicos e funcionais equilibrados, para proporcionar condições para a realização adequada quanto a tonicidade e mobilidade. Cabe ressaltar que as amostras apresentadas tiveram os objetivos propostos da pesquisa alcançados. Outras pesquisas deverão ser conduzidas para que os dados possam ser confirmados ou refutados. Outra limitação do presente trabalho refere-se à ausência de estudos sobre adesão à fonoterapia, impedindo, assim, a comparação dos achados.

\section{Considerações Finais}

Os dados encontrados no estudo evidenciam a ocorrência da classificação oclusal e fatores associados juntamente com a avaliação fonoaudiológica, diretamente associada à interdisciplinaridade da Fonoaudiologia com a Ortodontia, sendo essencial para a integridade do sistema estomatognático, pois a primeira trata os aspectos funcionais e a segunda os anatômicos. A relação entre essas ciências gera a harmonia do sistema, refletindo em saúde e bem-estar. A aproximação dessas áreas é relevante e crescente, objetivando complementação teórica e aperfeiçoamento profissional.

Mais estudos devem abranger a integralidade dos indivíduos para que exista ampliação do conhecimento dos profissionais sobre a sua área de atuação vinculada como trabalho conjunto, priorizando a qualidade de vida dos pacientes, uma vez que compreende a saúde pública.

\section{Agradecimentos}

À Deus por ter me dado saúde e força para superar as dificuldades. A minha família em especial a minha mãe Raimunda Nazaré, meu padastro Mario Cesár e minha sogra Maria de Nazaré, pelo amor incondicional, incentivo, apoio, por acreditar em mim e sempre está torcendo para que tudo dê certo em minha vida. Aos meus filhos José Neto e Maria Júlia, minha principal motivação diária para seguir em frente. Ao meu esposo Jaillon, que mesmos nos dias mais difíceis sempre esteve ao meu lado. As minhas amigas de turma Elizamar, Layla e Waldenia, pela determinação e otimismo durante a construção de nossos trabalhos. A minha amiga Marcilene por ter participado comigo no projeto de pesquisa da faculdade, sempre me encorajando. À todos os professores da instituição por repassarem seus conhecimentos, contribuindo no processo da minha formação profissional, em especial a minha professora e orientadora Priscila Cruz pela força, conselhos, dedicação, paciência e confiança.

\section{Referências}

Angle, E. H. (1899). Classification of Malocclusion. Dental Cosmos, Philadelphia, 41(3), 248-264.

Amaral, E. C., et al (2015). Inter-relação entre Odontologia e Fonoaudiologia. Rev CEFAC. 8(3), 326-8.

Brasil.(2020). Ministério da Saúde: Secretaria de Atenção em Saúde. Departamento de Atenção Básica.

Caetano, L. P. (2019). Relação entre respiração bucal desenvolvimento de más oclusões. Brazilian Journal of Surgery and Clinical Research, 27(3), 105-107, Jun - Ago.

Campos, F. L. et al. (2013). A má oclusão e sua associação com variáveis socioeconômicas, hábitos e cuidados em crianças de cinco anos de idade. Rev Odontol UNESP.MS, 3(42), 160-166.

Costa. M. et al. (2015) Achados da avaliação multiprofissional de crianças respiradoras orais. Rev. CEFAC. 3(17), 864-878.

Gupta, D. K. et al. (2016). Prevalência de má oclusão e avaliação das necessidades de tratamento em crianças maiores de $\beta$-talassemia. Prog Orthod, v 1, n 17, p 7. 
Research, Society and Development, v. 10, n. 1, e27610111714, 2021 (CC BY 4.0) | ISSN 2525-3409 | DOI: http://dx.doi.org/10.33448/rsd-v10i1.11714

Inagaki, T. L., et al. (2015). Atuação interdisciplinar odontologia: fonoaudiologia no tratamento de paciente com cárie precoce da infância. Rev. CEFAC. 2(17), 595-603.

Lucato, A. S., et al. (2010). Prevalência de má oclusão e sua relação com alterações funcionais na respiração e na deglutição. Braz Dent Sci. 8(13), 52-58.

Marcomini, L., et al. (2010). Prevalência de maloclusões e sua relação com alterações funcionais na respiração e deglutição. Braz. Dente Sci. 8(13), 52-58.

Moyers, R. E., et al. (1991). Classificação e terminologia da maloclusão. Ortodontia. Rio de Janeiro: Guanabara Koogan, 1991. 156-57.cap.9.

Narayanan, R. K., Jeseem, M. T., \& Kumar, T. V. A. (2016). Prevalence of Malocclusion among 10-12-yearold Schoolchildren in Kozhikode District, Kerala: An Epidemiological Study. Intituon J Clinica Pediatria Dental. 9(1), 50- 55.

Nascimento, S. G., et al.(2015). Relação entre respiração bucal desenvolvimento de má oclusões. Brazilian Journal of Surgery and Clinical Research Brasilia, 27(3), 105-107.

Organização Mundial de Saúde (2017). Levantamentos em saúde bucal. (5a ed.).

Pereira, A. S. et al. (2018). Metodologia da pesquisa cientifica. UFSM, NTE, RS

Ramalho, N. J. M., et al.(2016). Evaluation: integrative review. Rev Bras Enferm, 1(69), 162.

Ribeiro, S. T., \& Canto, L. G. (2014). Integração odontologia-fonoaudiologia: a importância da formação de equipes interdisciplinares. Rev. CEFAC, 2(16), 598-603.

Silva, T. R. (2014). Integração odontologia-fonoaudiologia: a importância da formação de equipes interdisciplinares. Rev CEFAC, $2(16)$, 598-603.

Silva, B. T. A., et al. (2015). Caracterização das funções orais de pacientes em tratamento ortodôntico na clínica infantil de odontologia da ufrn. Revista Eletrônica Gestão \& Saúde. 6(3), 2207-2227.

Sousa, M. T., et al. (2010). Revisão integrativa: o que é e como fazer. Rev Einstein, 8(1), 102.

Stetler, C. B., et al. (1998). Utilization-focused integrative reviews in a nursing service. Appl Nurs Res. 11(4), $195-206$. 